\title{
Giant renal artery aneurysm: A case report
}

\author{
Luca Cindolo $^{1}$, Manuela Ingrosso ${ }^{2}$, Piergustavo De Francesco ${ }^{2}$, Pietro Castellan ${ }^{2}$, \\ Francesco Berardinelli ${ }^{1}$, Franco Fiore ${ }^{3}$, Luigi Schips ${ }^{1}$ \\ ${ }^{1}$ Urology Dept, Robotic Unit, "S. Pio da Pietrelcina" Hospital, ASL Abruzzo 2, Italy; \\ ${ }^{2}$ Clinica Urologica, "SS. Annunziata" Hospital, ASL Abruzzo 2, Italy; \\ ${ }^{3}$ Vascular Surgery, "SS. Annunziata" Hospital, ASL Abruzzo 2, Italy.
}

\begin{abstract}
Summary A case of a $12 \mathrm{~cm}$ giant renal artery aneurysm (RAA) in an 59-year-old woman is reported. The patient was referred to our hospital for flank pain and spot hematuria. Ultrasonography (US) revealed some wide lacunar areas in her right kidney and a thin cortex. Three-dimensional computed tomography (3D-CT) revealed a giant right renal arteriovenous malformation (AVM). AngioCT scan showed a pervious right renal artery. The cavities of the right kidney were dilated and the parenchyma was markedly reduced. Two months later the patient underwent an open resection of the aneurysm and a right nephrectomy. She had an uneventful recovery and a healthy status (last follow-up: 9 month). In this particular case, a safe approach is the transabdominal approach since the aneurysm was very large, friable, and located on the right side. This report confirms the opportunity of a planned nephrectomy once there is adequate renal reserve in the opposite kidney using a midline approach.
\end{abstract}

KEY WORDS: Renal arteriovenous malformation; Renal artery aneurysms; Kidney; Surgical resection; Nephrectomy.

Submitted 14 January 2015; Accepted 19 March 2015

\section{INTRODUCTION}

The renal artery aneurysms (RAA) was mentioned for the first time in 1770 by Rouppe, who described the death of a sailor due to rupture of a large false aneurysm (1). Renal artery aneurysms are often diagnosed by ultrasound examination for the screening of hypertension. Many small aneurysms are repairable, in other large aneurysms nephrectomy may be required for the increased wall shear stress and the destruction of renal parenchyma (2). In recent years, coil embolization or stent-graft with the coil embolization was successful for treating RAAs and was indicated in that case of narrownecked, saccular, extra-parenchymal aneurysms (3). This paper will deal with the diagnosis and treatment of one giant symptomatic renal artery aneurysm.

\section{Case report}

A 59-year-old female patient who presented flank pain and spot hematuria was referred to our hospital. The patient had arterial hypertension in drug treatment and subclinical hypothyroidism in autoimmune thyroiditis. BMI was 30.4 and about 30 years ago she was undergone to right salpingectomy. Ultrasonography (US) revealed some wide lacunar areas in her right kidney and a thin cortex (Figure 1).
Three-dimensional computed tomography (3D-CT) revealed a giant right renal arteriovenous malformation (AVM) (Figure 2). The abdominal angioCT scan showed a pervious right renal artery, free from significant calcified and thrombotic parietal lesions. The artery provided for the supply of aneurysmal dilatation (maximum axial diameter of 7.5 and longitudinal extent of about $12 \mathrm{~cm}$ ), with calcified walls, that the lower third of the renal sinus stretched right up close to the ipsilateral iliac fossa. Dilatation appeared in communication with other vascular structures in the right kidney lodge, and confluent in ipsilateral renal vein; opacification was early in the arterial phase and in the inferior vena cava downstream of the confluence veins of the kidney. The cavities of the right kidney were moderately dilated and the parenchymal was markedly reduced (Figures 1 and 3). Two months later the patient underwent surgery, after careful evaluation together with vascular surgeons, the surgical consensus was in favor of a right nephrectomy and an excision of the aneurysm of the right renal artery, the patient was advised and she agreed. A chest X-ray showed a slight increase in the volume of left-sided heart, echocardiogram revealed neither cardiomegaly. The routine blood tests were normal, with creatinine 1.03 $\mathrm{mg} / \mathrm{dL}$ and $\mathrm{Hb} 13.6 \mathrm{~g} / \mathrm{dL}$. The surgical approach was laparotomy incision xipho-subumbilical, then, via transperitoneal, the left renal vein and the right renal artery were prepared near of the abdominal aorta. After opening the right paracolic gutter, the large aneurysm was displayed

Figure 1. Renal ultrasound scan showing some lacunar areas in right kidney and a thin cortex.

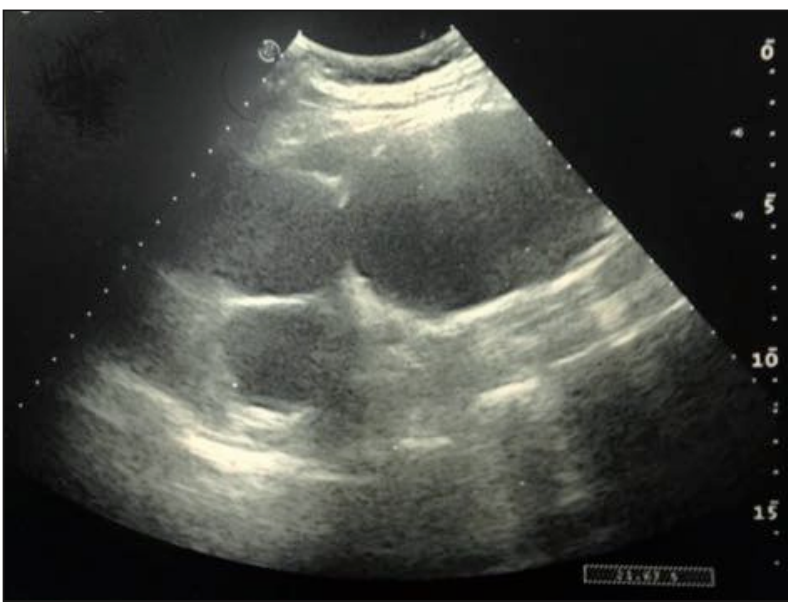


Figure 2. $3 D-C T$ scan showing a giant right renal arteriovenous malformation (A-B: $3 D$ reconstruction $A$-front view B-posterior view; C: cross-sectional image).

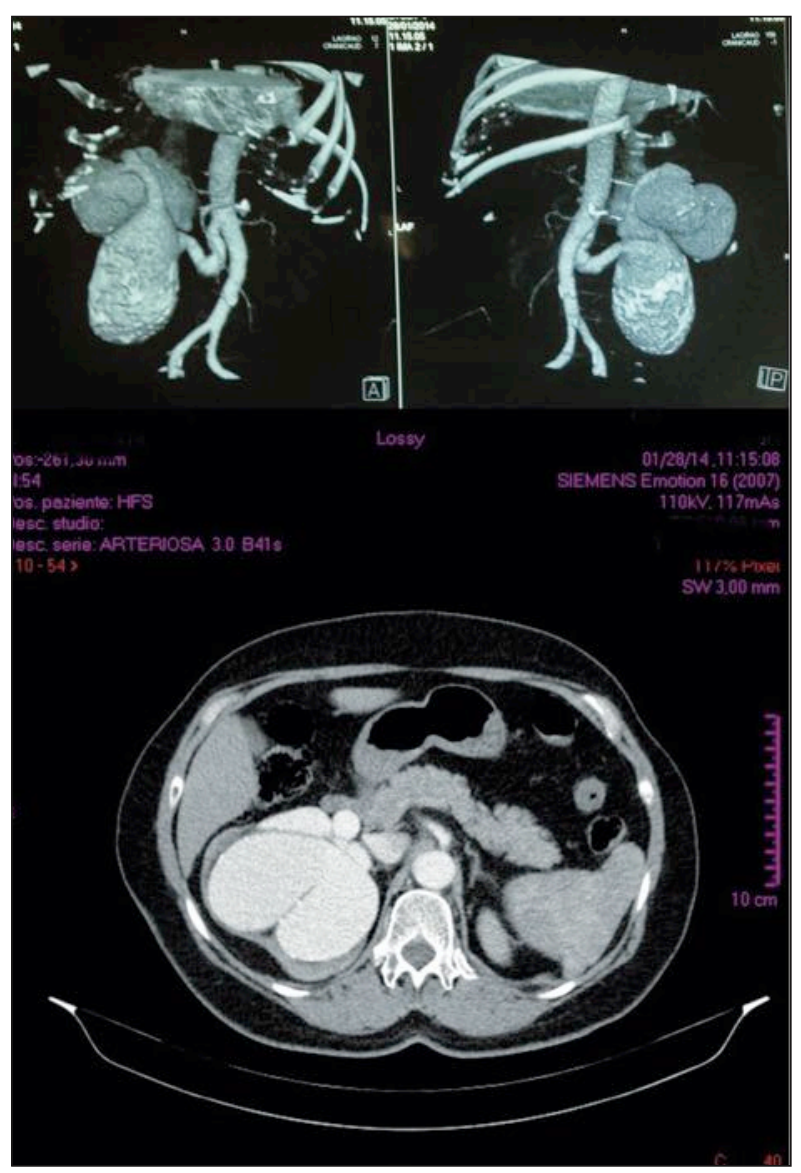

complications occurred in the postoperative period, without blood transfusions. The patient was discharged on the 5th postoperative day in good physical conditions with: $\mathrm{Hb}$ $10,6 \mathrm{~g} / \mathrm{dl}, 31 \% \mathrm{HCT}, \mathrm{WBC} 7.86 \times 10^{\wedge} 3 / \mathrm{ul}$, PLT $206 \times 10^{\wedge} 3$ $/ \mathrm{ul}$, creatinine $0.78 \mathrm{mg} / \mathrm{dL}$. Histological examination revealed a large aneurysm of the renal artery size of $8 \times 8.2 \times 4.5 \mathrm{~cm}$, with compression of the renal parenchyma, with diffuse glomerulosclerosis, interstitial inflammation, aspect pseudo-thyroid of tubular component and diffuse atrophy (Figure 4).

\section{Conclusions}

There are a lot of studies about RAAs, but little exists on treatment plans for GRAAs. It seems that most Giant RAAs are discovered when they are close to $10 \mathrm{~cm}$ in diameter and are usually part of the renal parenchyma. Arterial reconstruction or arterial embolization are not always an option since these patients may be elderly and have significant comorbidities. This report confirms the opportunity of a planned nephrectomy once there is adequate renal reserve in the opposite kidney using a midline approach. Discussion and supplementary references are posted on www.aiua.it

\section{REFERENCES}

1. Rouppe DL. Renalarteryaneurys. NovaActaPhysico-Medica Academiae Caesareae Leopoldino-Carolinae Naturae Curiosorum. $1770 ; 4: 76$

2. Hageman JH, Smith RF, Szilagyi E, Elliott JP. Aneurysms of the renal artery: problems of prognosis and surgical management. Surgery. 1978; 84:563-72.

3. Jibiki M, Inoue Y, Kudo T, Toyofuku T. Surgical Procedures for Renal Artery Aneurysms. Annals of Vascular Diseases. 2012; 5:157-160.
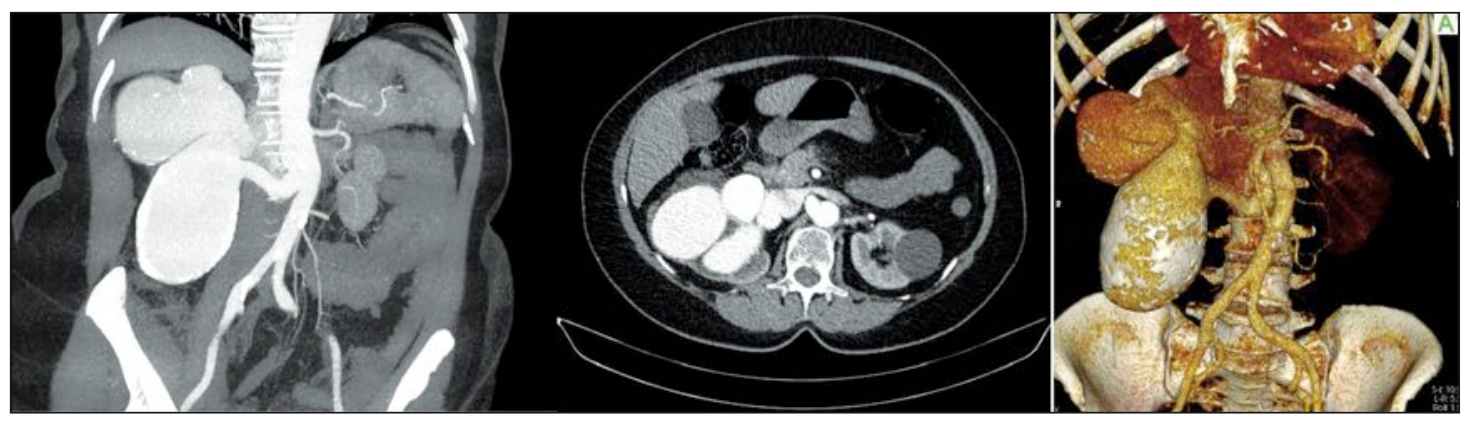

Figure 3.

ANGIO-TC and 3D

reconstruction confirming the dilatation of right kidney's cavity and reduction of right renal parenchyma (A: anterior-posterior axis; $B$ : transverse plane; $\mathrm{C}: 3 \mathrm{D}$ reconstruction).

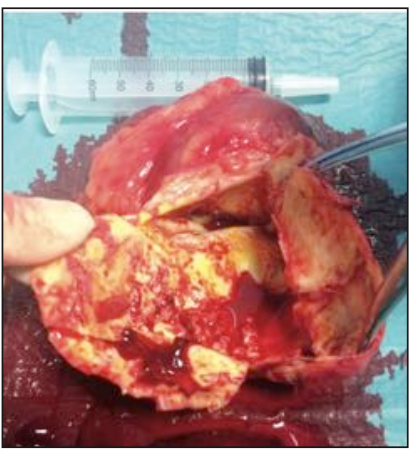

Figure 4. Postoperative view of the surgical specimen showing a large aneurysm of the renal artery size of $8 \times 8.2 \times 4.5$ $\mathrm{cm}$, with compression of the renal parenchyma.

below the kidney. The right renal vein (close to vena cava) and right renal artery (near renal hilum) were clamped and tied twice with Prolene 5/0. So right nephrectomy and excision of the aneurysm was practiced, after the closure of the ureter. Blood loss during surgery was about $150 \mathrm{ml}$. No

\section{Correspondence}

Luca Cindolo, MD - (Corresponding Author) lucacindolo@virgilio.it

Francesco Berardinelli, MD - berardinelli.francesco@gmail.com Luigi Schips, MD - luigischips@hotmail.com

Urology Dept, Robotic Unit, "S. Pio da Pietrelcina" Hospital

Via San Camillo De Lellis, 66054 Vasto (CH), Italy

Manuela Ingrosso, MD - manuela-ingrosso@hotmail.com Piergustavo De Francesco, MD - piergustavodf@hotmail.it Pietro Castellan, MD - castellanpietro@gmail.com

Clinica Urologica, "SS. Annunziata" Hospital

Via dei Vestini, 66100 Chieti, Italy

Franco Fiore, MD - f-fiore@outlook.it

Vascular Surgery, "SS. Annunziata" Hospital

Via dei Vestini, 66100 Chieti, Italy 